\title{
Magnetocaloric effect in Er-Al-Co bulk metallic glasses
}

\author{
HUI XiDong*, XU ZhiYi, WU Yuan, CHEN XiaoHua, LIU XiongJun \& LU ZhaoPing
}

State Key Laboratory for Advanced Metals and Materials, University of Science and Technology Beijing, Beijing 100083, China

Received July 18, 2011; accepted September 9, 2011

\begin{abstract}
A series of Er-Al-Co bulk metallic glasses (BMGs) have been prepared by the copper mold casting method. The glass forming ability and magnetocaloric effect (MCE) for these alloys have been investigated. The second-order magnetic transition from paramagnetic to ferromagnetic states takes place at about $9 \mathrm{~K}$. These BMGs exhibit excellent MCE because of their large effective magneton number; $\mathrm{Er}_{56} \mathrm{Al}_{24} \mathrm{Co}_{20}$ BMG has a maximum entropy change and refrigeration capacity of $16.06 \mathrm{~J} \mathrm{~kg}^{-1} \mathrm{~K}^{-1}$ and $546 \mathrm{~J} \mathrm{~kg}^{-1}$, respectively, under the field of $50 \mathrm{kOe}(10 \mathrm{kOe}=795.775 \mathrm{kA} / \mathrm{m})$ indicating that these BMGs are potential candidate magnetic materials for hydrogen liquefaction.
\end{abstract}

Er-Al-Co bulk metallic glasses, magnetocaloric effect, Curie temperature, refrigeration capacity

Citation: Hui X D, Xu Z Y, Wu Y, et al. Magnetocaloric effect in Er-Al-Co bulk metallic glasses. Chinese Sci Bull, 2011, 56: 3978-3983, doi: 10.1007/s11434$011-4855-7$

Early work on the magnetocaloric effect (MCE) of glassy alloys mainly focused on rapidly solidified rare earth or transition metal based ribbons. These glass ribbons were found to have large magnetic transition regions, and most of the $\mathrm{RE}_{1-x} M_{x}$ ( $M$ =transition metal) glassy alloys exhibit traditional MCE, i.e., their entropy changes are positive. For example, the maximum entropy change $\left(-\Delta S_{\max }\right)$ of $\mathrm{Gd}_{70} \mathrm{Fe}_{30}$ metallic glass is $1.5 \mathrm{~J} \mathrm{~kg}^{-1} \mathrm{~K}^{-1}$ under a magnetic field of $10 \mathrm{kOe}$ [1]. As the $\mathrm{Fe}$ in $\mathrm{Gd}_{70} \mathrm{Fe}_{30}$ is partially replaced by $\mathrm{Ni}$, the Curie temperature $\left(T_{\mathrm{c}}\right)$ of $\mathrm{Gd}_{70} \mathrm{Fe}_{12} \mathrm{Ni}_{18}$ glassy alloy decreases from 287.5 to $170 \mathrm{~K}$, and the $-\Delta S_{\max }$ reaches $7.71 \mathrm{~J} \mathrm{~kg}^{-1} \mathrm{~K}^{-1}$ under $70 \mathrm{kOe}$. When the $\mathrm{Fe}$ in $\mathrm{Gd}_{70} \mathrm{Fe}_{30}$ glassy alloy is completely replaced by $\mathrm{Ni}, T_{\mathrm{c}}$ and $-\Delta S_{\max }$ reach $126.3 \mathrm{~K}$ and $2.45 \mathrm{~J} \mathrm{~kg}^{-1} \mathrm{~K}^{-1}$, respectively $[1,2]$.

The exploration of the MCE of bulk metallic glasses (BMG) has attracted great attention in recent years. In 2002, Shen et al. [3] reported the MCE of $\mathrm{Pd}_{40} \mathrm{Ni}_{22.5} \mathrm{Fe}_{17.5} \mathrm{P}_{20} \mathrm{BMG}$, which exhibits a transition from superparamagnetic, to ferromagnetic to spin glass states with decreasing temperature. The paramagnetic-ferromagnetic transition temperature and $-\Delta S_{\max }$ of this glassy alloy under $50 \mathrm{kOe}$ are $94 \mathrm{~K}$ and

*Corresponding author (email: xdhui@ustb.edu.cn)
$0.58 \mathrm{~J} \mathrm{~kg}^{-1} \mathrm{~K}^{-1}$, respectively. In 2006, Luo et al. [4] investigated the $\mathrm{MCE}$ of $\mathrm{Gd}_{33} \mathrm{Er}_{22} \mathrm{Al}_{25} \mathrm{Co}_{20}$ and $\mathrm{Gd}_{53} \mathrm{Al}_{24} \mathrm{Co}_{20} \mathrm{Zr}_{3}$ BMG alloys. The $-\Delta S_{\max }$ 's of these glassy alloys reached 9.47 and $9.4 \mathrm{~J} \mathrm{~kg}^{-1} \mathrm{~K}^{-1}$ under $50 \mathrm{kOe}$. In 2007, Luo et al. [5] found another glass, $\mathrm{Er}_{50} \mathrm{Al}_{24} \mathrm{Co}_{20} \mathrm{Y}_{6}$, which exhibits a $-\Delta S_{\max }$ of $15.91 \mathrm{~J} \mathrm{~kg}^{-1} \mathrm{~K}^{-1}$. Meanwhile, Jo et al. [6] reported a new $\mathrm{Gd}_{55} \mathrm{Co}_{20} \mathrm{Fe}_{5} \mathrm{Al}_{20}$ BMG with $T_{\mathrm{c}}$ of $125 \mathrm{~K}$ and $-\Delta S_{\max }$ of $2.24 \mathrm{~J} \mathrm{~kg}^{-1} \mathrm{~K}^{-1}$ under $20 \mathrm{kOe}$. Very recently, a series of heavy rare earth based BMGs with large MCE including $\mathrm{Gd}_{56-x} \mathrm{Dy}_{x} \mathrm{Al}_{24} \mathrm{Co}_{20}(x=16,20,22)$ [7], $\mathrm{Gd}_{36} \mathrm{Y}_{20} \mathrm{Al}_{24} \mathrm{Co}_{20}$ [8], $\mathrm{Ho}_{36} \mathrm{Dy}_{20} \mathrm{Al}_{24} \mathrm{Co}_{20}$ [9], $\mathrm{Dy}_{36} \mathrm{Ho}_{20} \mathrm{Al}_{24} \mathrm{Co}_{20}$ [10] and $\mathrm{Er}_{36} \mathrm{Ho}_{20^{-}}$ $\mathrm{Al}_{24} \mathrm{CO}_{20}$ [11] were developed by the present author's group. Typically, $\mathrm{Gd}_{40} \mathrm{Dy}_{16} \mathrm{Al}_{24} \mathrm{Co}_{20}$ glassy alloy reaches $-\Delta S_{\max }$ of $15.78 \mathrm{~J} \mathrm{~kg}^{-1} \mathrm{~K}^{-1}$ under a field of $50 \mathrm{kOe}$.

The $-\Delta S_{\max }$ values of glassy alloys are not comparable to those of crystalline materials at the same magnetic field and temperature. This is because the field induced structural transitions are first-order in crystalline materials, but second-order transitions in glassy alloys. The lattice structure doesn't contribute to the MCE in glassy alloys. However, unlike crystalline materials which exhibit a sharp peak in their $-\Delta S_{\max }-T$ curves, glassy alloys usually have a relatively broad transition temperature range. Therefore, glassy alloys 
are more applicable for the Carnot cycle process. The main issue for glassy alloys is finding new compositions, which exhibit comparable $-\Delta S_{\max }$ values to crystalline materials whilst making the most of the special advantages of glassy alloys.

In this work, we report a series of Er-Al-Co bulk metallic glasses (BMGs) with excellent maximum entropy change and refrigeration capacity. The Curie temperature of these glassy alloys is about $9 \mathrm{~K}$, which is applicable to hydrogen liquefaction. It is believed that these glassy alloys are candidate magnetic materials to replace the paramagnetic salts (e.g. Gadolinium Gallium Garnet, GGG, which is usually used at a temperature lower than $10 \mathrm{~K}$ as a magnetic medium [12]) for cryogenic refrigeration.

\section{Materials and methods}

In this work, the compositions of Er-Al-Co ternary alloys were designated as shown in Figure 1. Because a high content of Er is beneficial to the MCE, we increased the Er to above $56 \%$ in these alloys. Ingots with the designed nominal compositions were first prepared by arc-melting a mixture of high-purity $\operatorname{Er}(99.95 \%), \mathrm{Al}(99.95 \%)$ and Co (99.95\%) under a Ti-gettered argon atmosphere. These ingots were remelted and injected into a copper mold to obtain cylindrical rod of $3 \mathrm{~mm}$ in diameter. The glassy structure of the as-cast rods was ascertained by using a Rigaku $\mathrm{D} / \mathrm{max}-3 \mathrm{~B}$ diffractometer with $\mathrm{Cu} \mathrm{K} \alpha$ radiation at $40 \mathrm{kV}$, and was further confirmed by using a Netzsch STA 449C differential scanning calorimeter. The magnetic properties were measured by a physical property measurement system (PPMS-9) from Quantum Design Company. The temperature dependence of the magnetization was obtained at a cooling rate of $1 \mathrm{~K} \mathrm{~min}^{-1}$ under a field of $200 \mathrm{Oe}$. The

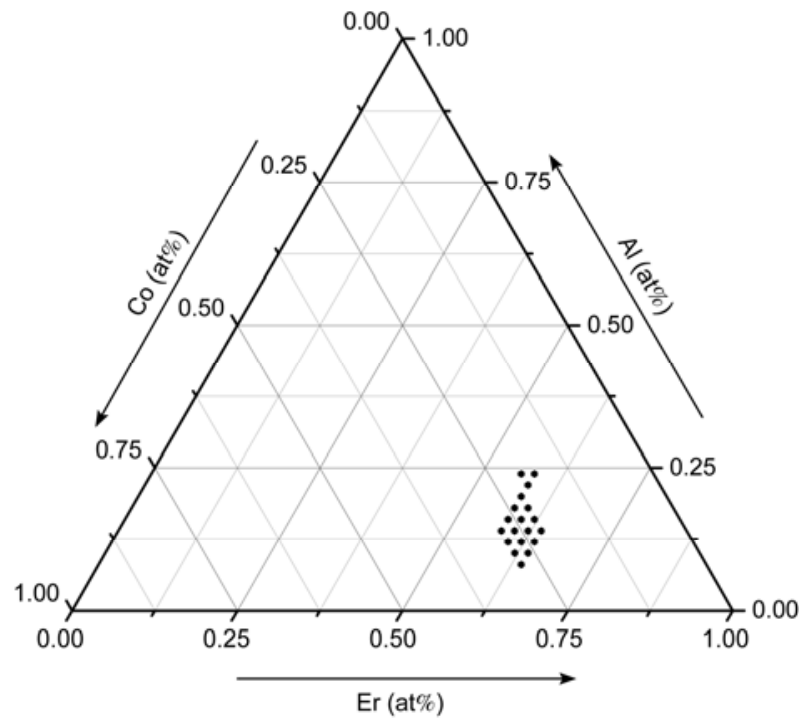

Figure 1 The compositions of Er-Al-Co ternary alloys. isothermal magnetization of the samples was measured under magnetic fields of $0-50 \mathrm{kOe}$ in the temperature range of $2-50 \mathrm{~K}$.

\section{Results and discussion}

The XRD patterns of the Er-Al-Co rods with diameters of 2-5 $\mathrm{mm}$ are shown in Figure 2. All the samples except for $\mathrm{Er}_{60} \mathrm{Al}_{12} \mathrm{Co}_{28}$ and $\mathrm{Er}_{60} \mathrm{Al}_{16} \mathrm{Co}_{24}$ exhibit characteristic features of amorphous structure, with halos at about $35^{\circ}$ and $60^{\circ}$. Glassy rods up to a critical diameter of $5 \mathrm{~mm}$ can be obtained for the $\mathrm{Er}_{56} \mathrm{Al}_{24} \mathrm{Co}_{20}$ alloy. Figure 3 shows the DSC traces of those samples with no obvious sharp peaks in their XRD curves. The traces show a glass transition region, followed by several exothermic peaks. The supercooled liquid region $\left(\Delta T_{x}\right)$ of $\mathrm{Er}_{56} \mathrm{Al}_{24} \mathrm{Co}_{20}$ alloy reaches $52.2 \mathrm{~K}$, indicating that this alloy has a relatively high glass forming ability, as evaluated by $\Delta T_{x}$.

Figure 4 shows the magnetization as a function of temperature under a field of $200 \mathrm{Oe}$ for $\mathrm{Er}_{56} \mathrm{Al}_{24} \mathrm{Co}_{20}, \mathrm{Er}_{58} \mathrm{Al}_{14^{-}}$ $\mathrm{Co}_{28}, \mathrm{Er}_{58} \mathrm{Al}_{24} \mathrm{Co}_{18}$ and $\mathrm{Er}_{58} \mathrm{Al}_{22} \mathrm{Co}_{20}$ (denoted as E1, E2, E3 and $\mathrm{E} 4$, respectively, for convenience in the following text) BMG alloys. From these magnetization curves, the Curie temperatures of these alloys can be derived by taking the derivative, $d M / d T$, as shown in Figure 5. Figure 4 shows that the magnetization of these glassy alloys initially decreases sharply and reaches zero with increasing temperature. There are sharp variations of the magnetization at $T_{\mathrm{c}}$, implying that a large entropy change may be expected in

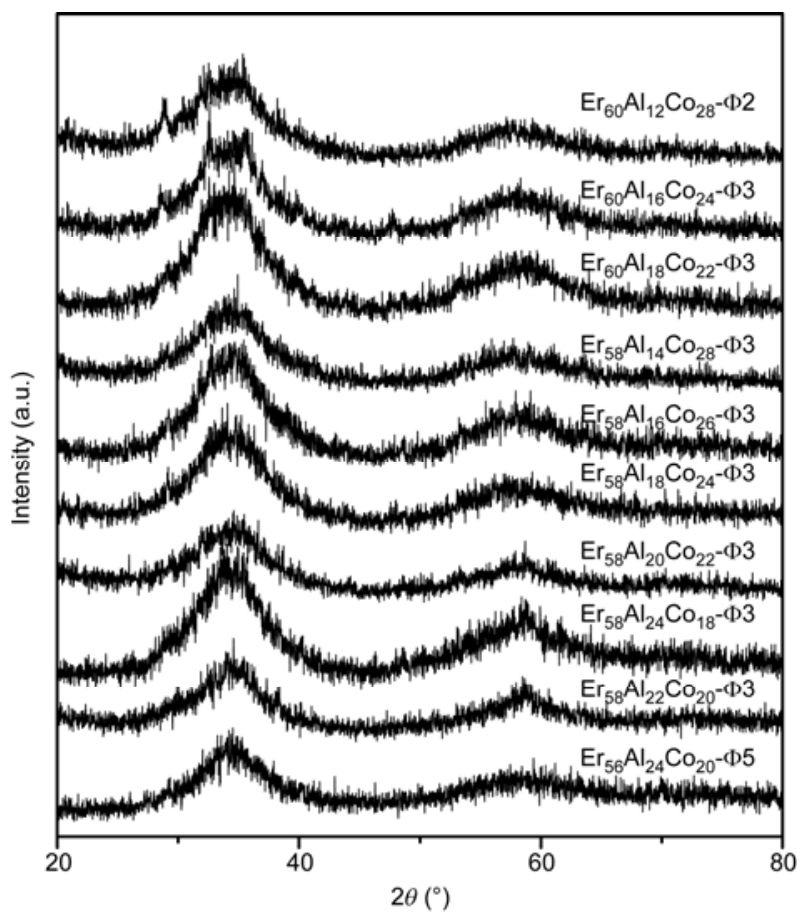

Figure 2 XRD patterns of Er-Al-Co alloys prepared by copper mold casting. 


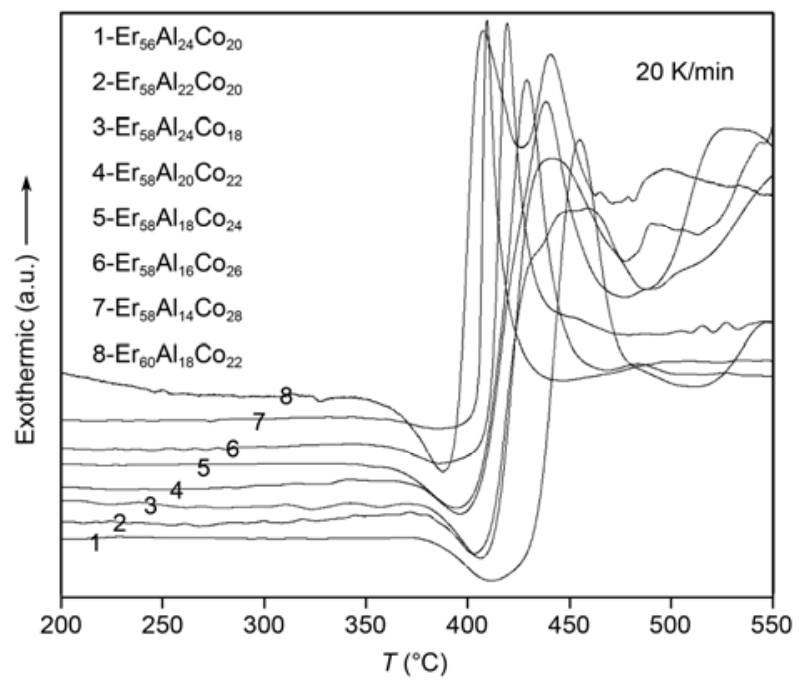

Figure 3 DSC traces of Er-Al-Co BMGs.

these glassy alloys according to the Maxwell relation. From Figure 5, the Curie temperatures of E1-E4 are 8.5, 8.6, 8.5 and $8.6 \mathrm{~K}$, respectively, which are very close to that of GGG paramagnetic salts. The sharp decrease in $T_{\mathrm{c}}$ of these glassy alloys can be explained by the molecular field theory. The $T_{\mathrm{c}}$ of a ferromagnet can be expressed by [13]

$$
T_{\mathrm{c}}=\frac{2 Z A_{\mathrm{ex}} J(J+1)}{3 k_{\mathrm{B}}},
$$

where $Z$ is the coordinate number which is usually equal to

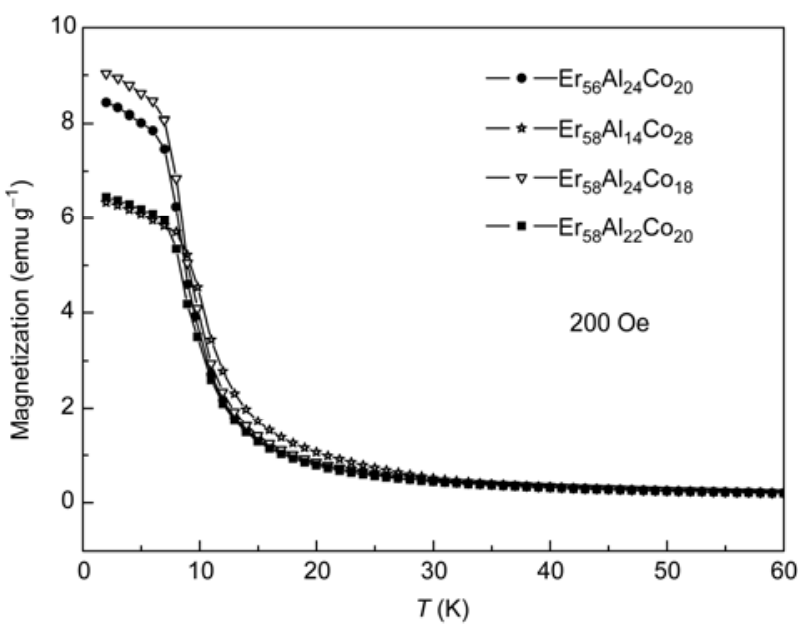

Figure 4 The magnetization as a function of temperature for Er-Al-Co BMG alloys under a field of 200 Oe.

12 [14], $A_{\text {ex }}$ the exchange integral, $J$ the total angular momentum, and $k_{\mathrm{B}}$ the Boltzmann constant. This equation suggests that the decrease of $T_{\mathrm{c}}$ is probably caused by a difference in exchange integral or angular momentum. The decrease in these two factors may be attributed to the formation of amorphous structure. In glassy alloys, both the alloying effect and lack of long range order result in the decrease of these two constants. The local concentration heterogeneity in glassy alloys may enhance the fluctuations in the exchange integral and further decrease these two factors.

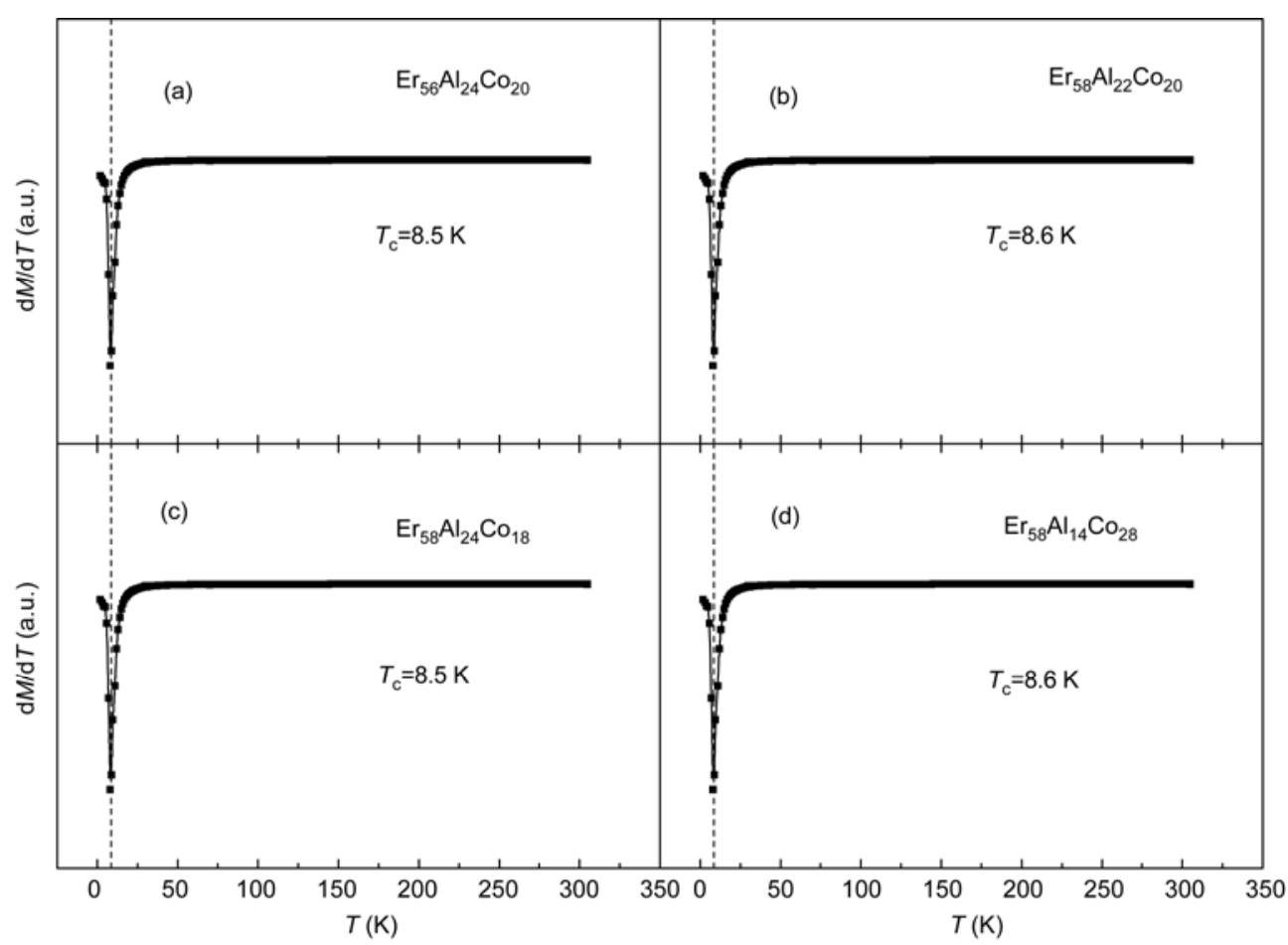

Figure 5 The Curie temperature of Er-Al-Co BMGs measured under a field of $200 \mathrm{Oe}$. 
The relationship between the magnetic susceptibility $(\chi)$ and temperature can also be obtained from the $M-T$ curve. As shown in Figure $6, \chi$ changes linearly with the temperature below $10 \mathrm{~K}$, and is accordance with the Curie-Weiss law [15]

$$
\chi=\frac{C}{T-\Theta_{\mathrm{f}}}
$$

where $C=\frac{N \mathrm{p}^{2} \mu_{\mathrm{B}}{ }^{2}}{3 k_{\mathrm{B}}}, N$ is the density of particles, and $p$ is the effective magneton number, which can be expressed as

$$
p^{2}=\frac{3 k_{\mathrm{B}} M}{B N_{\mathrm{A}} \mu_{\mathrm{B}}^{2}}
$$

where the unit of $B$ is Oe $\mathrm{g} \mathrm{emu}^{-1} \mathrm{~K}^{-1}, M$ is $\mathrm{g} \mathrm{mol}^{-1}, N_{\mathrm{A}}=$ $6.02 \times 10^{23} \mathrm{~mol}^{-1}, \mu_{\mathrm{B}}=9.3 \times 10^{-21} \mathrm{emu}, k_{\mathrm{B}}=1.38 \times 10^{-23} \mathrm{~J} \mathrm{~K}^{-1}$, $1 \mathrm{~J}=10^{7}$ Oe emu. Hence

$$
p=\sqrt{7.95 \frac{M}{B}}
$$

By fitting the linear curves of the magnetic susceptibility dependence of temperature, we calculate the effective magneton numbers for E1-E4 as 7.00, 7.03, 7.43 and 7.04, respectively. Considering that the $-\Delta S_{\max }$ is related to the effective magneton number, these four glassy alloys are expected to have large $-\Delta S_{\max }$.

Figure 7 shows the field dependence of magnetization from 2 to $45 \mathrm{~K}$ for E1-E4 glassy alloys up to a field of

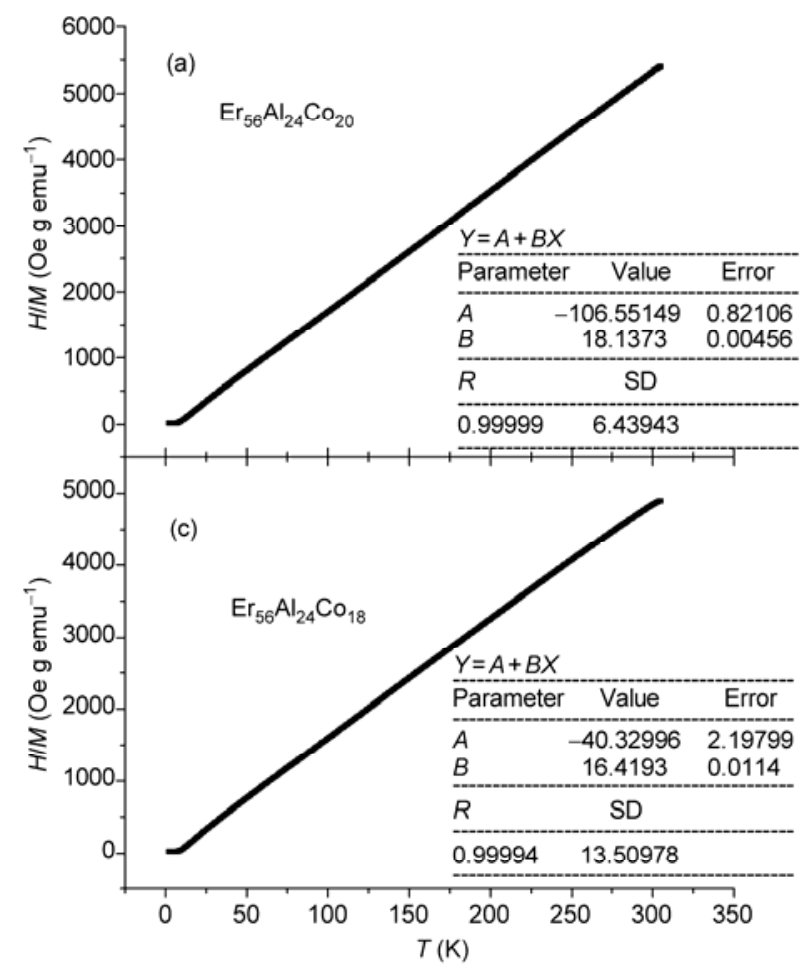

Figure $6 H / M(1 / \chi)-T$ curves of Er-Al-Co BMGs under a field of 200 Oe.
50 kOe. Obvious magnetic transitions from the ferromagnetic to the paramagnetic state can be seen. To determine the features of these magnetic transitions, the Arrott curve of $\mathrm{Er}_{56} \mathrm{Al}_{24} \mathrm{Co}_{20}$ was derived, as shown in Figure 8. An S-type of shape does not occur, and the slope is positive, indicating that the magnetic transition is of second order.

The relationship between magnetic field and magnetization can be described by the Maxwell law

$$
\left(\frac{\partial S_{\mathrm{M}}}{\partial B}\right)_{T}=\left(\frac{\partial M}{\partial T}\right)_{B},
$$

where $B=\mu_{0} H$, and $\mu_{0}$ is the magnetic susceptibility in vacuum. During an isothermal process, the magnetic entropy can be obtained as

$$
\begin{aligned}
\Delta S_{\mathrm{M}}(T, H) & =S_{\mathrm{M}}(T, H)-S_{\mathrm{M}}(T, 0) \\
& =\int_{0}^{H} \mu_{0}\left[\frac{\partial M(T, H)}{\partial T}\right]_{H} \mathrm{~d} H .
\end{aligned}
$$

Figure 9 shows the magnetic entropy change and adiabatic temperature change calculated from eq. (6). The temperatures where $-\Delta S_{\max }$ occurs are a little bit higher than the corresponding $T_{\mathrm{c}}$ values. The magnetic entropy changes are $16.06,15.71,15.50$ and $15.67 \mathrm{~J} \mathrm{~kg}^{-1} \mathrm{~K}^{-1}$, respectively, for E1-E4 alloys. It is seen that the $-\Delta S_{\max }$ of E1 alloy is even larger than those of $\mathrm{Er}_{50} \mathrm{Al}_{24} \mathrm{Co}_{20} \mathrm{Y}_{6}$ and $\mathrm{Gd}_{40} \mathrm{Dy}_{16} \mathrm{Al}_{24} \mathrm{Co}_{20}$, which exhibit an $-\Delta S_{\max }$ of 15.91 [7] and $15.78 \mathrm{~J} \mathrm{~kg}^{-1} \mathrm{~K}^{-1}$ [5], respectively under the field of $50 \mathrm{kOe}$. Figure 9 also shows that the full widths at half maximum of the peaks

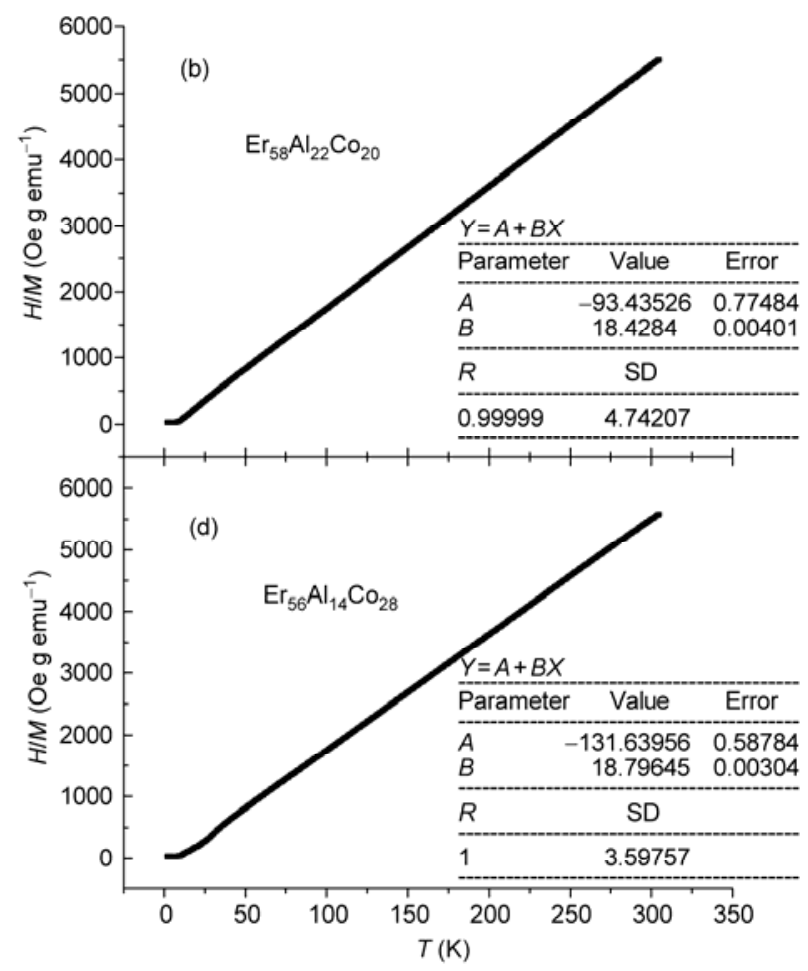



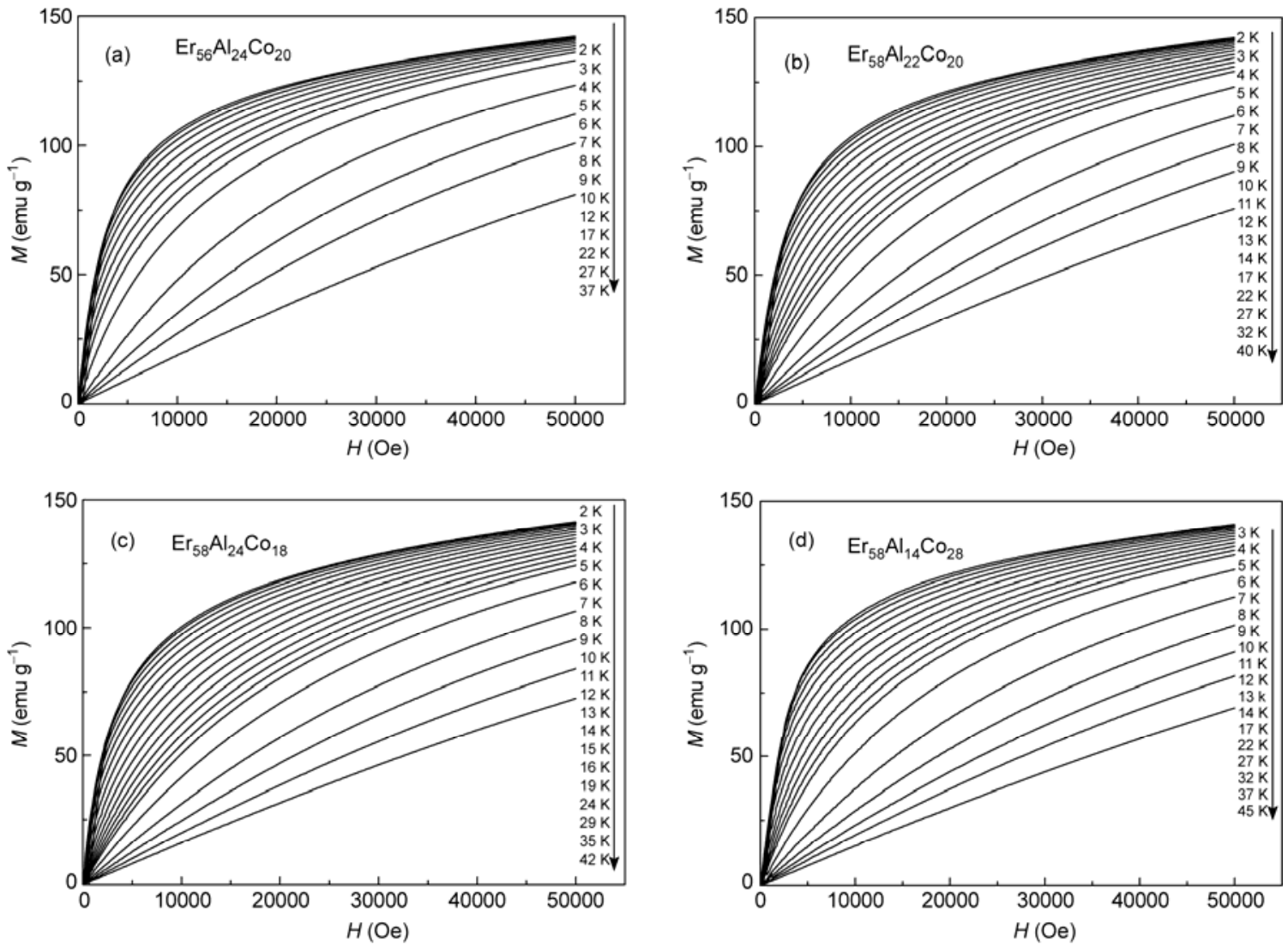

Figure 7 The field dependence of the isothermal magnetization for E1-E4 glassy alloys from 2 to $45 \mathrm{~K}$ up to a field of $50 \mathrm{kOe}$.

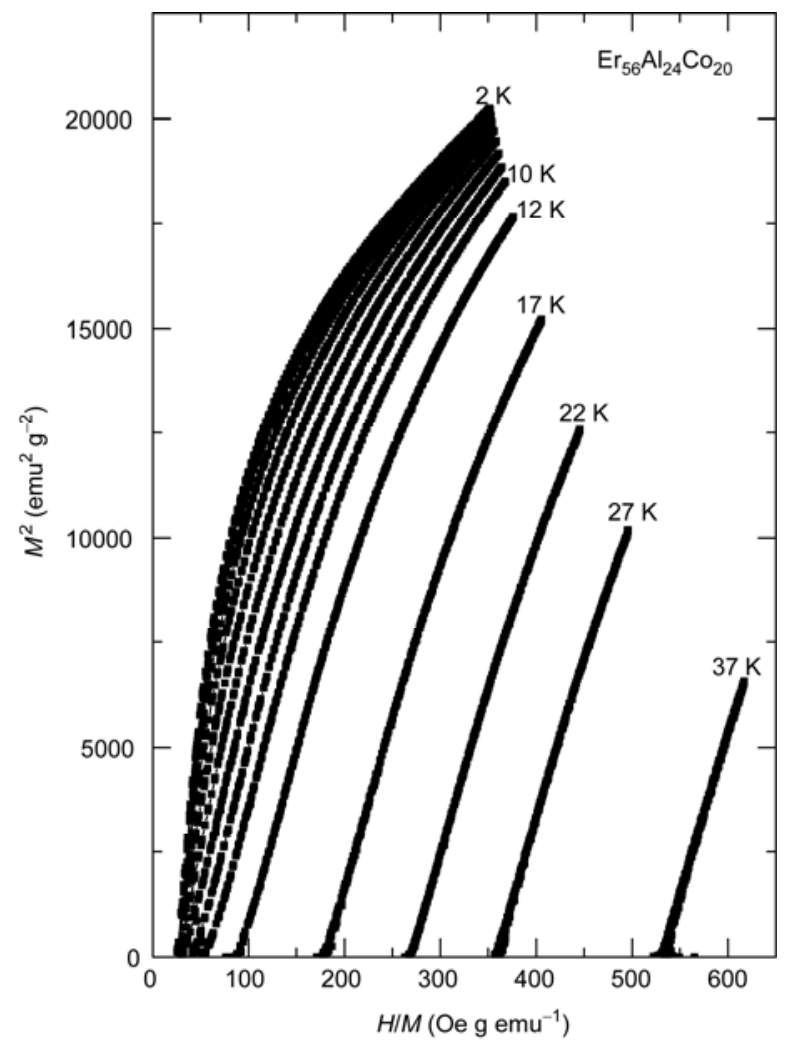

Figure 8 The Arrott curve for $\mathrm{Er}_{56} \mathrm{Al}_{24} \mathrm{Co}_{20}$ BMG.

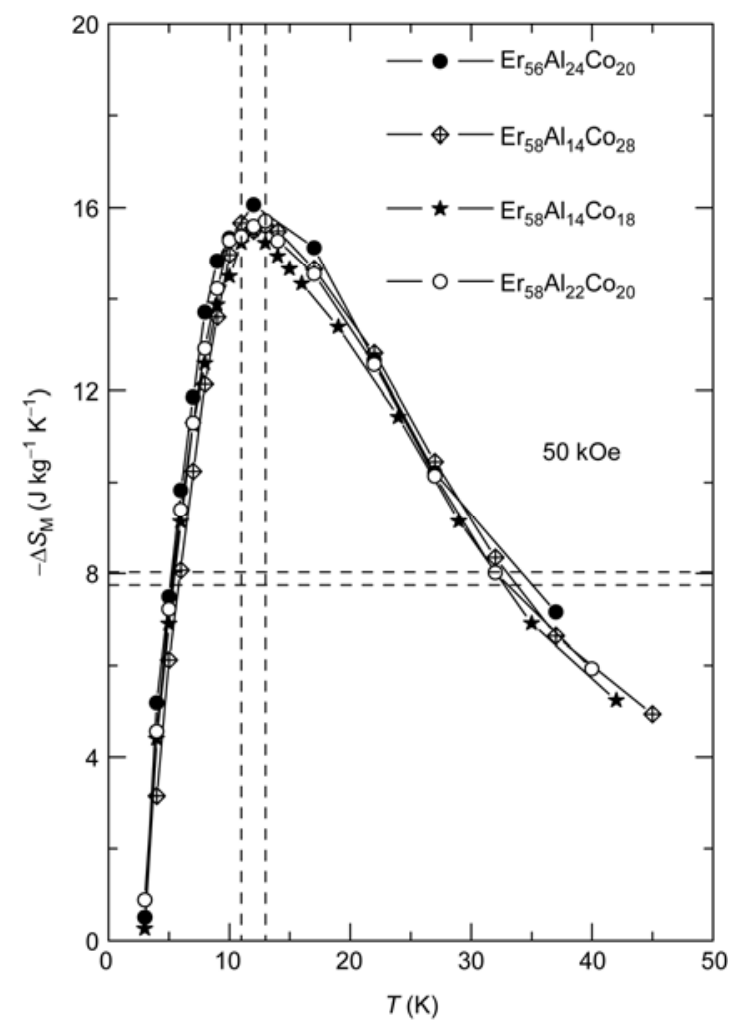

Figure 9 The isothermal magnetic entropy changes of Er-Al-Co BMGs under a field of $50 \mathrm{kOe}$ 
(FWHM) for E1-E4 are broad. The maximum FWHM of these alloys reaches $32 \mathrm{~K}$. On the other hand, the performance temperature (i.e. the region between the lowest and highest temperature of the FWHM) ranges from 5-30 K. This value is $10 \mathrm{~K}$ higher than that of the GGG paramagnetic salt, indicating that the glassy alloys are more applicable to cryogenic refrigeration in the range of the hydrogen liquefaction temperature. From the products of FWHM and $-\Delta S_{\max }$, the refrigeration capacities of E1-E4 are 465.7, 432.0, 427.8 and $431.0 \mathrm{~J} \mathrm{~kg}^{-1}$, respectively.

\section{Conclusions}

(1) A series of Er-Al-Co ternary BMGs were prepared by using copper mold casting. The XRD and DSC measurements show that $\mathrm{Er}_{56} \mathrm{Al}_{24} \mathrm{Co}_{20}$ exhibits a relatively high GFA among the alloys of interest.

(2) The Curie temperatures of E1-E4 BMGs are at about $9 \mathrm{~K}$, and their effective magneton numbers are 7.00, 7.03, 7.43 and 7.04, respectively. The magnetic transition from the ferromagnetic to the paramagnetic state for these glassy alloys is of the second order.

(3) E1-E4 BMGs show excellent MCE and refrigeration capacities. The $-\Delta S_{\max }$ of $\mathrm{E} 1 \mathrm{BMG}$ is even larger than those of $\mathrm{Er}_{50} \mathrm{Al}_{24} \mathrm{Co}_{20} \mathrm{Y}_{6}$ and $\mathrm{Gd}_{40} \mathrm{Dy}_{16} \mathrm{Al}_{24} \mathrm{Co}_{20}$ BMGs, indicating that the Er-Al-Co BMG prepared in this work is a potential candidate magnetic material for hydrogen liquefaction.

This work was supported by the National Natural Science Foundation of China (50871013 and 51071018) and the National Basic Research Program of China (2007CB613901).
1 Foldeaki M, Gopal B R, Chahine R, et al. Composition dependence of magnetic properties in amorphous rare-earth-metal-based alloys. J Magn Magn Mater, 1997, 174: 295-308

2 Liu X Y, Barclay J A, Gopal B R, et al. Thermomagnetic properties of amorphous rare-earth alloys with Fe, Ni, or Co. J Appl Phys, 1996, 79: $1630-1641$

3 Shen T D, Schwarz R B, Coulter J Y, et al. Magnetocaloric effect in bulk amorphous $\mathrm{Pd}_{40} \mathrm{Ni}_{22.5} \mathrm{Fe}_{17.5} \mathrm{P}_{20}$ alloy. J Appl Phys, 2002, 91: 5240-5245

4 Luo Q, Zhao D Q, Pan M X, et al. Magnetocaloric effect in Gd-based bulk metallic glasses. Appl Phys Lett, 2006, 89: 081914

5 Luo Q, Zhao D Q, Pan M X, et al. Magnetocaloric effect of Ho-, Dy-, and Er-based bulk metallic glasses in helium and hydrogen liquefaction temperature range. Appl Phys Lett, 2007, 90: 211903

6 Jo C-L, Xia L, Ding D, et al. Glass formation ability, structure and magnetocaloric effect of a heavy rare-earth bulk metallic glassy $\mathrm{Gd}_{55} \mathrm{Co}_{20} \mathrm{Fe}_{5} \mathrm{Al}_{20}$ alloy. J Alloys Compd, 2008, 458: 18-21

7 Liang L, Hui X, Chen G L. Thermal stability and magnetocaloric properties of GdDyAlCo bulk metallic glasses. Mater Sci Eng B, 2008, 147: 13-18

8 Liang L, Hui $\mathrm{X}$, Wu $\mathrm{Y}$, et al. Large magnetocaloric effect in $\mathrm{Gd}_{36} \mathrm{Y}_{20} \mathrm{Al}_{24} \mathrm{Co}_{20}$ bulk metallic glass. J Alloy Compd, 2008, 457: 541-544

9 Liang L, Hui X, Zhang C M, et al. A novel $\mathrm{Ho}_{36} \mathrm{Dy}_{20} \mathrm{Al}_{24} \mathrm{Co}_{20}$ bulk metallic glass with large magnetocaloric effect. Solid State Commu, 2008, 146: 49-52

10 Liang L, Hui X, Zhang C M, et al. A Dy- based bulk metallic glass with high thermal stability and excellent magnetocaloric properties. $\mathrm{J}$ Alloy Compd, 2008, 463: 30-33

11 Liang L, Hui X, Zhang C M, et al. An Er- based bulk metallic glass with high thermal stability and excellent magnetocaloric properties. Intermetallics, 2008, 16: 198-201

12 McMichael R D, Ritter J J, Shull R D. Enhanced magnetocaloric effect in $\mathrm{Gd}_{3} \mathrm{Ga}_{5-x} \mathrm{Fe}_{x} \mathrm{O}_{12}$. J Appl Phys, 1993, 73: 6946-6948

13 Mathias G. Fundamentals of Magnetism. Berlin: Springer, 2008

14 Mansuripur M, Ruane M F. Mean-field analysis of amorphous rare earth-transition metal alloys for thermomagnetic recording. IEEE Trans Magn, 1986, 22: 33-43

15 Kittel C. Translated by Xiang J Z, Wu X H. Solid Physics, 8th ed. Beijing: Chemistry Engineering Press, 2008

Open Access This article is distributed under the terms of the Creative Commons Attribution License which permits any use, distribution, and reproduction in any medium, provided the original author(s) and source are credited. 